\title{
Coronary No Reflow at PCI Site Indicator
}

National Cancer Institute

\section{Source}

National Cancer Institute. Coronary No Reflow at PCI Site Indicator. NCI Thesaurus.

Code C119331.

An indication as to whether there is a new acute reduction in flow at the original percutaneous coronary intervention site in the coronary vessel. 